\title{
Incidence, clinical characteristics, and short-term prognosis of angina pectoris
}

\author{
Manish M Gandhi, Fiona C Lampe, David A Wood
}

\begin{abstract}
Objectives-To estimate the clinical incidence and short-term prognosis of patients presenting with typical angina pectoris in the general population.

Design-Prospective survey of all patients referred by 117 general practitioners from a random sample of 17 general practices serving a population of 191677 with a median follow up of 16 months.

Setting-A special open access chest pain clinic, based in the non-invasive cardiology department of a teaching hospital, set up for this study.

Patients -110 consecutive patients $\leqslant 70$ years age with no history of coronary heart disease presenting for the first time with typical angina.
\end{abstract}

Main outcome measures-Age and sex specific incidences, persistence of chest pain, revascularisation procedures, myocardial infarction, and death.

Results-The crude annual incidence of angina pectoris ( $95 \%$ confidence interval) was $0.83(0.66$ to 1.0$)$ per thousand population aged 31-70 years; the rates were $1.13(0.85$ to 1.40$)$ for men and $0.53(0.33$ to 0.72 ) for women. On resting electrocardiography $5 \%$ of patients had $\geqslant 1 \mathrm{~mm}$ horizontal or downsloping ST depression, 5\% had Q/QS patterns, and in one (1\%) there was complete left bundle branch block. Among the 103 patients who underwent a Bruce protocol exercise test, $29 \%$ had $\geqslant 3 \mathrm{~mm}$ ST segment depression induced at a low workload. Of 107 patients at a median (range) follow up of 15.8 (7-30) months, angina remitted spontaneously in 12 patients $(11 \%), 20$ (19\%) underwent revascularisation, eight (7\%) sustained a non-fatal myocardial infarction, and four (4\%) died.

Conclusion-Incidence of new cases of angina pectoris in the United Kingdom is conservatively estimated from this study to be 22600 patients per annum. Almost one third of these patients will have positive exercise tests at low workload, so the potential for coronary angiography and revascularisation is considerable. With one in 10 patients experiencing a nonfatal myocardial infarction or coronary death within a year of presentation the prognosis of angina is not benign. Further research is required to identify those patients in the general population who would benefit most from coronary revascularisation.

(Br Heart f 1995;73:193-198)

Keywords: angina pectoris, prognosis, incidence.

Angina pectoris affects about two million men and women in the United Kingdom. ${ }^{12}$ In up to two thirds of patients, angina results in absence from work, and affects sporting, sexual and other daily living activities. ${ }^{3} \mathrm{~A}$ patient with angina consults a general practitioner two to three times a year ${ }^{4}$ and has a threefold increased risk of developing unstable angina, myocardial infarction, or cardiac death within two years of first presentation. ${ }^{5}$

Although treatment other than medication to improve the quality of life, ${ }^{6}$ relieve symptoms $^{7}$ and prolong survival ${ }^{8}$ in selected patients with angina is now available, little is known about the incidence or clinical course of this disease in the general population since the advent of coronary intervention procedures. The Framingham Study, which started in 1949, was unique in recording incidence of angina in both men and women in the USA in the prerevascularisation era, ${ }^{9}$ but this description is now outdated as both incidence of, and mortality from, cardiovascular diseases have declined. ${ }^{10}$

Most patients with angina initially present to their general practitioner. Less than one fifth are referred for hospital investigation ${ }^{11}$ usually when medical therapy is insufficient to control symptoms. Studies of hospital patients therefore provide no information about new patients who are not referred but who subsequently experience a myocardial infarction or sudden death. The limited number of community studies are all from the prerevascularisation era when sublingual nitrates were the mainstay of angina therapy..$^{912-14}$ There are no contemporary data on the incidence and outcome of unselected patients with angina pectoris.

The aim of this prospective study was therefore to determine the incidence, clinical characteristics and short-term prognosis of men and women up to the age of 70 years in the general population presenting with angina 
pectoris as the initial manifestation of coronary heart disease.

\section{Patients and methods \\ STUDY POPULATION}

All 117 general practitioners from a random sample of 17 general practices serving a population of 191677 in Southampton agreed to participate in the study. They agreed to refer all men and women up to and including the age of 70 years presenting for the first time with chest pain which in their opinion could be stable angina. Patients presenting with recurrent chest pain in whom previous episodes were not suspected to be coronary heart disease and those prescribed a trial of sublingual nitrates for any other reason were also eligible for referral. Patients with any previous diagnosis of coronary, congenital or valvular heart disease, cardiomyopathy, on long-term antianginal therapy, or with chest pain consistent with unstable angina or evolving myocardial infarction which required hospital admission were excluded.

\section{CHEST PAIN CLINIC}

Referrals were assessed within $24 \mathrm{~h}$ by a cardiologist at a dedicated chest pain clinic, which was specially set up for the study at the Royal South Hants Hospital in Southampton, and to which the sample of general practitioners had open access from Monday to Friday between 9:00 am and 1:00 pm. After a full history and complete clinical examination of the patient, typical angina was diagnosed if each of the following criteria of an anatomically ${ }^{15}$ and prognostically ${ }^{5}$ validated definition was present: recurrent, brief episodes of chest pain (up to $15 \mathrm{~min}$ ) precipitated by exertion or by exertion and emotion and relieved by rest or nitroglycerin, and whose character and radiation were consistent with the diagnosis. Unless contraindicated a treadmill exercise test according to the Bruce protocol was carried out on all patients with angina 2-6 days after diagnosis. The extent of any horizontal or downsloping ST segment depression was measured $80 \mathrm{~ms}$ after the J point.

After the initial clinic visit, the general practitioner was responsible for subsequent management and follow up. The chest pain clinic was not situated at the same site as the regional cardiac centre, and decisions to undertake coronary angiography and revascularisation were made independently by cardiologists at the regional centre unaware of the follow up study.

\section{FOLLOW UP}

Morbidity and mortality follow up data were collected for all patients with typical angina. The cause of death was ascertained from the patient's general practitioner. A questionnaire requesting information about current medication, persisting chest pain, attendance at outpatient clinics and hospital admissions was posted to all surviving patients.

All questionnaire responses were corroborated with the patient's hospital clinical records. Myocardial infarction was recorded when it was documented by the admitting team based on the history and a twofold rise in cardiac enzymes and/or characteristic electrocardiographic changes. A search of the register in the cardiac catheterisation laboratory at the regional cardiac centre identified patients with angina who had undergone coronary angiography. Clinical summaries were obtained from case notes of patients reviewed at the cardiac centre, including any who had undergone percutaneous transluminal coronary angioplasty or coronary artery bypass grafting.

\section{STATISTICAL ANALYSIS}

Incidence per thousand per year with $95 \%$ confidence intervals (CI) were calculated for the total population aged $31-70$ years and for age and sex specific subgroups. These were calculated as the number of cases of typical angina divided by the number of person years at risk during the study period $\times 1000$. The age and sex distribution of the population at risk was obtained from the registers of the participating general practices. Age and sex specific incidences were applied to the 1991 United Kingdom population projections to estimate the number of new angina cases each year. ${ }^{16}$ Clinical outcome was assessed in relation to the first of the following events: death, myocardial infarction, percutaneous transluminal coronary angioplasty, and coronary artery bypass grafting. A survival curve was constructed using the Kaplan-Meier technique to demonstrate the cumulative probability of event-free survival during the follow up period.

\section{Results}

\section{INCIDENCE}

A total of 110 new consecutive patients (70 male and 40 female) with typical angina were prospectively identified between June 1990 and March 1992 from 467 patients referred for assessment by general practitioners covering a total registered population of 191677 .

Age and sex specific incidences for typical angina were derived from the known age and sex structure of the total study population for the study period between January 1991 and March 1992 (fig 1). The crude annual incidence $(95 \% \mathrm{CI})$ in men and women aged $31-70$ years was $1.13(0.85,1.40)$ and 0.53 $(0.33,0.72)$ per thousand population per year respectively. The overall crude annual incidence of typical angina was $0.83(0.66,1.0)$ per thousand patients aged $31-70$ years per year.

Applying these rates to the United Kingdom population gives an estimate of 22 570 (95\% CI 17840,27 030) new patients presenting to their general practitioner with typical angina each year.

\section{CLINICAL CHARACTERISTICS}

Ninety two per cent of patients had been resident in the area of study for over 10 years. The duration of symptoms varied: $39 \%$ 
Table 1 Clinical characteristics of 110 consecutive patients presenting with angina pectoris from a randomly selected general population sample

\begin{tabular}{|c|c|}
\hline & $n(\%)$ \\
\hline $\begin{array}{l}\text { Mean (SD) age (years) } \\
\text { Male gender }\end{array}$ & $\begin{array}{l}57 \cdot 4(9 \cdot 6) \\
70(64)\end{array}$ \\
\hline Smoking habit & \\
\hline Current & $33(30)$ \\
\hline Ex smokers & $47(43)$ \\
\hline $\begin{array}{l}\text { Pipe/cigar } \\
\text { Life long non-smoker }\end{array}$ & \\
\hline $\begin{array}{c}\text { Life long non-smoker } \\
\text { Body mass index }\left(\mathrm{kg} / \mathrm{m}^{2}\right)\end{array}$ & $25(23)$ \\
\hline$<25$ & $24(22)$ \\
\hline $25-29$ & $55(50)$ \\
\hline $\begin{array}{l}\geqslant 30 \\
\text { Hypertension }^{\star}\end{array}$ & $\begin{array}{l}30(27) \\
53(48)\end{array}$ \\
\hline $\begin{array}{l}\text { Hypertension } \\
\text { Cholesterol (mmol/l) }\end{array}$ & \\
\hline $\begin{array}{l}<6.5 \\
6.5-7.9\end{array}$ & $\begin{array}{l}26(25) \\
49(47)\end{array}$ \\
\hline & $29(28)$ \\
\hline $\begin{array}{l}\text { Diabetes mellitus } \dagger \\
\text { Resting ECG }\end{array}$ & $9(9)$ \\
\hline $\begin{array}{l}\text { Resting ECG } \\
\geqslant 1 \mathrm{~mm} \mathrm{STD}\end{array}$ & $5(5)$ \\
\hline $\begin{array}{l}\mathrm{Q} / \mathrm{S} \neq \\
\mathrm{LBBB}\end{array}$ & $5(5)$ \\
\hline $\begin{array}{l}\text { LBBB } \\
\text { Exercise ECG }\end{array}$ & \\
\hline$\geqslant 1 \mathrm{~mm}$ STD & $63(61)$ \\
\hline
\end{tabular}

STD, horizontal or downsloping ST segment depression; LBBB, left bundle branch block.

${ }^{\star} \mathrm{BP} \geqslant 160 / 100 \mathrm{~mm} \mathrm{Hg}$ or patient receiving antihypertensive medication; trandom glucose $>11 \mathrm{mmo} / \mathrm{l}$ or patient receiving medication; frandom glucose $>11 \mathrm{mmo} / /$ or patient receiving medication; $¥$ Minnesota code $1 \cdot 1,1 \cdot 2$.

Because some values are missing the denominator ranges from 100 to 110 .

reported symptoms for less than one month, $36 \%$ between 1 and 4 months, $15 \%$ between 4 and 12 months, and in $10 \%$ symptoms were present for more than a year. Some $34 \%$ experienced angina daily, $52 \%$ had symptoms at least once a week, and for the remaining $14 \%$ the frequency was less than this. Table 1 shows the clinical characteristics of patients at presentation.

As treadmill exercise testing was carried out on all patients with typical angina who did not have contraindications, separate estimates were derived for incidence of new patients with angina and an ischaemic exercise test response. Of the 103 patients who underwent exercise testing, $63(61 \%)$ had an ischaemic response with $\geqslant 1 \mathrm{~mm}$ horizontal or downsloping ST segment depression. In the United Kingdom, the annual incidence of new patients with typical angina and exercise induced ischaemic ST segment depression is estimated at $9730(95 \%$ CI 7760 , $11450)$ men and 4240 (95\% CI 2890, 5330) women.

Table 2 Outcome of patients presenting with typical angina in the general population

\begin{tabular}{llllc}
\hline & $\begin{array}{l}\text { Outcome } \\
\text { Male } \\
(n=69)\end{array}$ & $\begin{array}{l}\text { Female } \\
(n=38)\end{array}$ & $\begin{array}{l}\text { Months to } \\
\text { event (median) }\end{array}$ & $\begin{array}{l}\text { Total events } \\
(\%)\end{array}$ \\
\hline $\begin{array}{l}\text { No of patients who died } \\
\text { No of patients who had }\end{array}$ & 4 & 0 & 2.6 & 3.7 \\
$\begin{array}{l}\text { myocardial infarction } \\
\text { No of patients who underwent }\end{array}$ & 6 & 2 & 1.6 & 7.5 \\
$\begin{array}{l}\text { PTCA } \\
\text { No of patients who underwent } \\
\text { CABG† }\end{array}$ & 9 & 3 & 2.9 & 11.2 \\
\hline
\end{tabular}

PTCA, percutaneous transluminal coronary angioplasty; CABG, coronary artery bypass grafting. ${ }^{\star}$ Excluding one female patient on waiting list; $\dagger$ excluding one female and two male patients on waiting list.

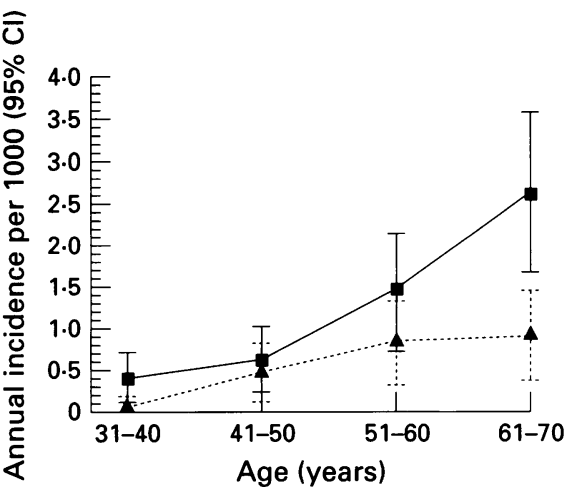

$\begin{array}{lcccc} & 31-40 & 41-50 & 51-60 & 61-70 \\ \text { Male } & 0.40 & 0.63 & 1.47 & 2.62 \\ & (0 \cdot 10,0 \cdot 70) & (0.24,1 \cdot 02) & (0.79,2 \cdot 14) & (1.67,3.58) \\ \text { Female } & 0.06 & 0.47 & 0.85 & 0.91 \\ & (0,0.18) & (0 \cdot 12,0.82) & (0.32,1.37) & (0.32,1.45)\end{array}$

Figure 1 Annual age and sex specific incidence rates of angina pectoris. $\mathbf{\square}$, men; $\boldsymbol{\Delta}$, women; CI, confidence interval.

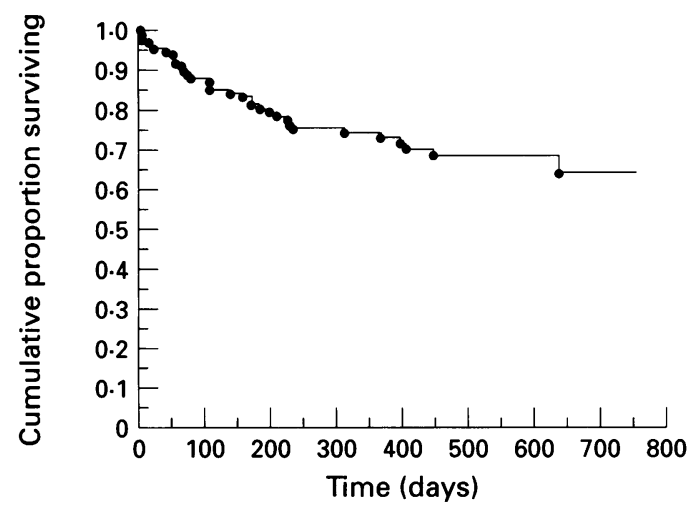

Figure 2 Event-free survival of patients with typical angina at a median of 15.8 months after first presentation.

OUTCOME

The median (range) duration of follow up was $15 \cdot 8$ (7-30) months. Complete data were available for $107(97 \%)$ of 110 patients with typical angina. The three patients lost to follow up had moved without a forwarding address.

Table 2 shows outcome and fig 2 the cumulative event-free survival for the total

$R \times$ no chest pain
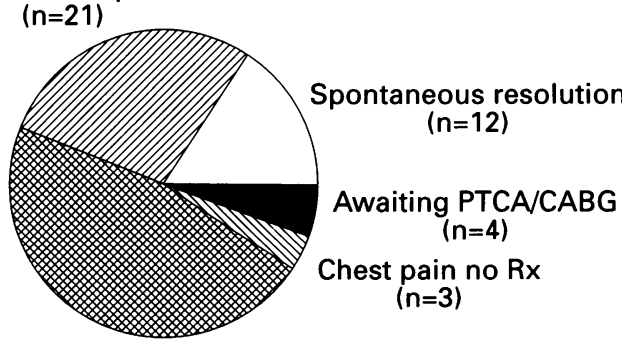

Chest pain, $\mathrm{Rx}$ $(n=35)$

Figure 3 Outcome in 75 surviving patients who had not undergone revascularisation or experienced a non-fatal myocardial infarction at follow up. $R x$, antianginal medication; PTCA, percutaneous transluminal coronary angioplasty; $C A B G$, coronary artery bypass grafting. 
cohort of patients with typical angina in the study. Eleven per cent of patients presenting with angina died $(n=4)$ or experienced myocardial infarction $(n=8)$ and $19 \%(n=$ 20) underwent revascularisation. One of the deaths occurred in a patient with a low workload positive exercise test who also had coexisting prostatic malignancy. There were no special arrangements with the regional cardiac centre for patients assessed at the chest pain clinic and the decision for elective revascularisation was made independently by the cardiologists concerned based on their usual clinical practice.

Fig 3 shows the outcome among the 75 surviving patients who had not undergone revascularisation or experienced a non-fatal myocardial infarction at the time of follow up.

Angina resolved spontaneously in 12 patients $(11 \%)$, and with medical therapy in a further $21(20 \%)$. About one third of patients $(33 \%)$ reported continuing symptoms despite medication, and a further four (4\%) were awaiting elective revascularisation. Three patients who reported continuing chest discomfort were not receiving medical treatment.

\section{Discussion}

The main objective of this study was to determine the clinical incidence and outcome of angina pectoris in a wide range of unselected patients representative of this manifestation of coronary heart disease in the general population. As in the Framingham study, the diagnosis of angina was based on a clinical history. In the absence of routine cardiac catheterisation, the proportion of patients with "significant" angiographic coronary artery stenosis is not known. However, this historical definition is independently associated in both men and women with a threefold increased risk of a non-fatal or fatal cardiac event within 2 years of diagnosis ${ }^{5}$ and is highly predictive of coronary artery disease especially in men. ${ }^{15}$ As general practitioners agreed to refer all new patients to a dedicated chest pain clinic, this study provides a clinically useful estimate of the incidence and prognosis of this disease in the population.

The crude incidence rate of angina in the present study is lower than previously reported $^{91213}$ and whilst differences among countries, patient populations, methods and periods of study make direct comparisons difficult, it is consistent with the decline in mortality from coronary heart disease in these countries over the period of these surveys, and with the reported $27 \%$ fall in the incidence of angina in 50-59 year old men in the Framingham cohort between 1950 and $1970 .{ }^{10}$ Although general practitioners agreed to refer all new patients with angina at the time of presentation, we may have underestimated the incidence of angina to the extent that patients who do not report their symptoms to their general practitioner are not included. This conservative bias also applies to a survey carried out in the early 1970 s of new and worsening angina which was also based on referrals from general practitioners and a cardiological diagnosis. ${ }^{14}$ Biennial reviews of the entire population in the Framingham study retrospectively identified new cases of angina from a cardiological assessment identical to that employed in our study. ${ }^{9}$ By reviewing the entire Framingham population it was also possible to identify retrospectively those who had developed angina since the previous examination and subsequently had a myocardial infarction or died. Whilst this approach reduces the possibility of bias from under reporting it does not permit contemporaneous assessment of clinical and exercise characteristics before treatment or progression to myocardial infarction and death, which is a unique feature of our study.

Incidence of angina increased in both sexes with age, but at all ages it was higher in men (fig 1). Men aged 61-70 years had a fourfold higher incidence compared with that of 41-50 year old men and an almost threefold higher incidence compared with that of women of the same age. The lower incidence of angina in women in this study is consistent with the experience of Framingham women who, over 26 years, experienced half the coronary heart disease morbidity of men. ${ }^{17}$ In that study, however, the incidence of angina in women above the age of 75 years was higher than in men.

Not surprisingly the prevalence of modifiable cardiovascular risk factors in newly diagnosed angina patients was common. Up to one third of patients smoked cigarettes and about one quarter of them were obese. Over one third had raised blood pressure $(\geqslant 160 / 100 \mathrm{~mm} \mathrm{Hg})$. which was unrecognised, recognised but not treated, or inadequately controlled on treatment. Over half of the angina cases had a total cholesterol concentration sufficiently high to justify further investigation with a view to dietary, and where appropriate, drug treatment. In all but one patient raised cholesterol levels were unrecognised before clinical presentation with angina. Electrocardiography at rest revealed ST segment abnormalities in only a small minority, but on exercise there was objective evidence of ischaemia in almost two thirds of patients with angina with marked ischaemia in over one quarter to justify further investigation.

The prognosis of patients who present to a general practitioner with exertional chest pain was not benign. About $11 \%$ in our study experienced non-fatal myocardial infarction or death within 1 year of initial diagnosis. Some have suggested classifying new onset angina as "unstable" implying the need for urgent treatment, ${ }^{18}$ but this is of little practical value to a general practitioner for whom patients who ultimately follow a chronic stable course also present with "new onset" exertional chest pain. Extrapolating our data to the United Kingdom suggests that over 2000 patients with exertional chest pain present each year to general practitioners a few months before experiencing their first nonfatal or fatal myocardial infarction. Although the rates of myocardial infarction and death in 
men in the current study are similar to rates reported in a community study of men with unstable angina from selected general practices in Edinburgh, ${ }^{14}$ they could underestimate the national rate for several reasons. First, elective revascularisation in almost one fifth of patients may have averted an adverse outcome in a proportion of these patients. Second, as in a previous study, ${ }^{19}$ it is possible some patients with chest pain did not present to their general practitioner or were not referred to the clinic for assessment, but subsequently experienced a cardiac event. The likelihood of this occurring in our survey is small because the general practitioners agreed to refer all patients and the provision of an open access chest pain service where such patients could be seen within $24 \mathrm{~h}$ of presentation made referrals to any other part of the medical service unlikely. Furthermore, it is known that patients who report their symptoms to a doctor tend to have prognostically more important disease compared with those who do not report their symptoms. ${ }^{20}$ Lastly, because of known regional variation in the incidence of coronary heart disease ${ }^{21}$ and a lower standardised mortality ratio in the southwest, ${ }^{22}$ the incidence of, and mortality from, angina in other parts of the United Kingdom are likely to be higher.

As in previous studies of angina in the population in which spontaneous remission of chest pain occurred in $14-39 \%$ of patients after different follow up periods, ${ }^{13} 1423$ we too observed spontaneous remission of symptoms in $11 \%$ of patients, and with concomitant medical therapy in a further $19 \%$. The reason for disappearance of symptoms without medication in this small proportion of patients is unclear. Angina is a clinical syndrome and therefore it is difficult to be certain whether remission is part of the natural history of the disease or was related to an "incorrect" initial diagnosis. ${ }^{23}$

The combined event rate for myocardial infarction and cardiac death in the current study was higher than the rate of cardiac events in patients with effort related angina admitted to a district general hospital. ${ }^{24}$ In their prospective survey of admissions in whom cardiac enzymes had been measured, Murphy et $a l^{24}$ excluded patients with a confirmed myocardial infarction, and divided the remaining 141 patients with angina into three categories: effort angina diagnosed by a modified Rose questionnaire, patients with confirmed prior infarction and those admitted with ST-T changes in association with chest pain. In contrast to the present study in which four deaths and eight myocardial infarctions were recorded within one year among 110 patients with angina who were ambulant, none of the 35 patients with effort angina in that study experienced such events during the first four months after admission, and only two events $(6 \%)$ were recorded in the group after three years. A study based on "survivors" who reach hospital partly explains their low event rate. More importantly, their results underline the poor sensitivity of a Rose chest pain questionnaire diagnosis of angina for cardiac mortality. A diagnosis of angina based on a history elicited by a physician in the Framingham study, ${ }^{9}$ as used in the present study, had a higher sensitivity for cardiac mortality than the Rose questionnaire used in the Whitehall study. ${ }^{25}$

Comparison of revascularisation rates between the current study and that of Murphy et $a l^{24}$ reveals striking differences-19\% of community based ambulant patients with typical angina, the majority of whom had normal resting electrocardiograms, underwent a coronary revascularisation procedure within one year in the current study, compared with only 9\% (six of 67) of patients with chest pain and resting ST-T changes who underwent revascularisation within three years of hospital admission. ${ }^{24}$ One could speculate that had the revascularisation rate in the present study population been lower, then the rate of fatal or non-fatal myocardial infarction might have been higher. If this was true, then it would be of concern to note that as little as $20 \%$ of patients with angina in the population are referred by general practitioners for cardiological investigation. ${ }^{11}$

This is the first study to investigate the clinical incidence and prognosis of angina pectoris since the advent of coronary revascularisation procedures. A major strength of this study is its representativeness of clinically incident angina pectoris in a general population. Incidences in our population confirm a persisting sex differential in coronary heart disease and are consistent with the falling mortality from this disease. These results from a south of England population require confirmation in other parts of the country.

Almost two thirds of patients presenting with angina in our population have objective evidence of ischaemia on exercise testing and nearly one third have marked ischaemia which, according to current guidelines, ${ }^{26}$ would justify further investigation including coronary arteriography. With one in 10 of all patients having a non-fatal myocardial infarction or dying in the short term, an important question is raised: does early investigation and revascularisation in patients presenting with angina, regardless of whether symptoms are medically controlled, ${ }^{27}$ reduce morbidity and mortality? Our study illustrates the compelling need for evidence from randomised intervention studies so that physicians can make rational rather than empirical decisions about the optimal timing of coronary intervention to improve the prognosis of angina pectoris in the population. ${ }^{28}$ If interventions are to have a significant impact on outcome, they may need to be performed over a much shorter time scale than is currently usual in this country.

This study was coordinated from the Department of Medicine (cardiology), University of Southampton, Royal South Hant Hospital. We thank the 117 general practitioners for thei enthusiastic participation; Karen Taylor and Linda Truscot (Senior Chief Physiological Measurement Technicians), and all staff of the non-invasive cardiology department at the Royal South Hants Hospital for their assistance with the chest pain clinic; Ann Coulthart, Cardiology Department, Roya Infirmary, Edinburgh for Minnesta Coding of ECGs; the 
Preventive Cardiology Trust (administrator $\mathrm{Mr}$ Dennis Urquhart) which administers the Jeffrey Fryer bequest, Baye UK, and Boehringer Ingelheim for educational grants; Dr $\mathrm{N}$ Conway, Dr K Dawkins and Dr H Gray for allowing acces to patients' case notes; and Avis Scantlebury for administration.

1 Shaper A, Cook D, Walker M, Macfarlane P. Prevalence of ischaemic heart disease in middle aged British men Br Heart $\mathcal{F} 1984 ; 51: 595-605$.

2 Smith W, Kenicer M, Tunstall-Pedoe H, Clark E Crombie I. Prevalence of coronary heart disease in Scotland: Scottish heart study. Br Heart $\mathcal{f} 1990 ; 64$ : 295-8.

3 Research Committee, Northern Region Faculty, Royal College of General Practitioners. Study of angina in patients aged 30 to 59 in general practice. $B M \mathcal{F} 1982$ 285:1319-21.

4 Royal College of General Practitioners, Office of Population Censuses and Surveys. Morbidity statistics from general practice 1981-82 (third national study). London: HMSO, 1986. (Series MB5, No 1:23.)

5 Murabito J, Anderson K, Kannel W, Evans J, Levy D. Risk of coronary heart disease in subjects with chest discomfort: the Framingham heart study. $\mathrm{Am} f \mathrm{Med}$ 1990;89:297-302.

6 Coronary artery surgery study (CASS). A randomised trial of coronary artery bypass surgery. Quality of life in patients randomly assigned to treatment groups. patients randomly assign

7 RITA trial participants. Coronary angioplasty versus coronary artery bypass surgery: the randomised intervention treatment of angina (RITA) trial Lancet 1993;341: 573-80.

8 Varnauskas E, and the European Coronary Surgery Study Group. Twelve year follow-up of survival in the randomized European coronary surgery study. $N$ Engl $f \mathrm{Med}$ 1988;319:332-7.

9 Kannel W, Feinleib M. Natural history of angina pectoris in the Framingham study. Am 7 Cardiol 1972;29:154-63.

10 Sytkowski P, Kannel W, D'Agostino R. Changes in risk factors and the decline in mortality from cardiovascula disease. $N$ Engl f Med 1990;322:1635-41.

11 Cannon PS, Connell PA, Stockley IH, Garner ST, Hampton JR. Prevalence of angina as assessed by a survey of prescriptions for nitrates. Lancet 1988;i:979-81

12 Medalie J, Goldbourt U. Angina pectoris among 10,000 men. Am $\mathcal{F}$ Med 1976;60:910-21.
13 Fry $\mathrm{J}$. The natural history of angina in a general practice. $f R$ Coll Gen Pract 1976;26:643-6.

14 Duncan B, Fulton M, Morrison S, Lutz W, Donald K, Kerr F, et al. Prognosis of new and worsening angina pectoris. BMF 1976;1:981-5.

15 Weiner D, Ryan T, McCabe C, Kennedy J, Schloss M, Tristani F, et al. Correlations among history of angina, ST-segment response and prevalence of coronary artery disease in the coronary artery surgery study (CASS). $N$ Engl F Med 1979;301:230-5.

16 Office of Population Censuses and Surveys Monitor. Office of Population Censuses and Surveys. London: HMSO, 1993. (Series PP2, No 18.)

17 Lerner D, Kannel W. Patterns of coronary heart disease morbidity and mortality in the sexes: a 26-year follow-up morbidity and mortality in the sexes: a 26-year follow-up of the Frat

18 Braunwald E. Unstable angina: a classification. Circulation 1989;80:410-4

19 Fulton M, Lutz W, Donald K, Kirby B, Duncan B, Morrison $S$, et al. Natural history of unstable angina. Lancet 1972;i:860-5.

20 Rose G, Baxter J, Reid D, McCartney P. Prevalence and prognosis of electrocardiographic findings in middleaged men. Br Heart $\mathcal{F} 1978 ; 40: 636-43$

21 Garg R, Madans J, Kleinman J. Regional variation in ischemic heart disease incidence. $\mathcal{F}$ Clin Epidemiol 1992; 45:149-56.

22 Office of Population Censuses and Surveys. Mortality statistics. London: HMSO, 1991. (Series DH5, No 16.)

23 Kannel W, Sorlie P. Remission of clinical angina pectoris: the Framingham study. Am $\mathfrak{f}$ Cardiol 1978;42:1 19-23.

24 Murphy J, Connell P, Hampton J. Predictors of risk in patients with unstable angina admitted to a district patients with unstable angina admitted to

25 Bulpitt C, Shipley M, Demirovic J, Ebi-Kryston K, Markowe H, Rose G. Predicting death from coronary heart disease using a questionnaire. Int $\mathcal{f}$ Epidemiol 1990; 19:899-904.

26 de Bono DP, Hopkins A. The investigation and management of stable angina. Report of a Working Party of the Joint Audit Committee of the British Cardiac Society and the Royal College of Physicians of London. $\mathcal{F} R$ Coll Physicians Lond 1993;27:267-73.

27 Anon. Pandora's angina. Lancet 1992;339:782-3.

28 Gandhi MM, Lampe FC, Wood DA. Management of angina pectoris in general practice: a questionnaire survey of general practitioners. Br $\mathcal{F}$ Gen Pract 1995; in press. 